\title{
PREPARATION FOR RESEARCH AND THE DOCTOR'S DEGREE IN MATHEMATICS.
}

\section{REPORT OF THE AMERICAN SUBCOMMITTEE OF THE INTER- NATIONAL COMMISSION ON THE TEACHING OF MATHEMATICS.*}

THe following institutions are mentioned in this report:

Brown, $\nmid$ Bryn Mawr, California, $\nmid$ Chicago, Cincinnati, Clark, Columbia, Cornell, Harvard, Illinois, Indiana, Johns Hopkins, Kansas, Michigan, Minnesota, Missouri, Nebraska, Northwestern, Pennsylvania, Princeton, Stanford, Syracuse, Virginia, Wisconsin, Yale.

The requirements for the degree of doctor of philosophy in mathematics are not exactly defined in all the above institutions. As a matter of fact, the policy is in force in some of them of definitely advising aspirants for the doctorate to complete their graduate studies at other universities in which graduate faculties in mathematics have long been strong and active. It is, however, clear that this condition is but temporary. The increase in the number of strong men in mathematics is resulting in added strength in an increasing number of institutions. It is, therefore, certain that the number of universities in which graduate work will be carried to a definite conclusion will be greater in the immediate future than at present.

On the other hand, in those universities in which within the past ten years three or more doctorates have been awarded there is a degree of uniformity in the requirements which probably indicates and establishes a standard for the United States - the outgrowth of conditions peculiar to the educational system of this country. This standard may be described by detailing the course and career of a successful candidate in some one of these institutions.

For admission to registration as a candidate for the doctorate, successful completion of an undergraduate course terminating

\footnotetext{
* International Commission on the Teaching of Mathematics. Committee XIV. - Graduate Work in Universities. Subcommittee 2-Preparation for Research and the Doctor's Degree. Chairman, P. F. SMrTh, Yale University ; MAX MASON, University of Wisconsin ; E. J. WILCZYNSKI, University of Chicago ; J. I. Hutchinson, Cornell University ; G. D. BirkhoFf, Princeton University. This report was submitted to the Commissioners in December, 1910.

† Data taken from catalogues and necessarily incomplete.
} 
with a bachelor's degree is required. While all undergraduate degrees cannot at the present time be regarded as equivalent in educational units, greater uniformity in the future will result from the standardizing influence in this direction of the Carnegie Foundation for the Advancement of Teaching.

In his undergraduate years, the candidate has pursued courses in mathematics including the calculus, and in some instances also mechanics, projective geometry, advanced calculus, and theory of functions. In any case the courses mentioned are regarded as introductory, and are required before advanced study begins. A reading knowledge of French and German is prescribed. The course of advanced study upon which the candidate now enters extends usually over three years. This time may, however, be spent in residence at one or more universities, with the exception of the final third year. During this year, the candidate must reside at the university from which he desires his academic degree. The instruction during the period mentioned is for the most part by lectures combined with work in the seminary prepared and delivered by the candidate and his fellow students under the critical eyes of their professors. There may be no formal examinations during this period. The responsibility of mastering his courses rests upon the candidate. In addition to mathematics, one or two minor subjects are required, usually in applied mathematics. This portion of the requirement may, in some cases, be successfully met before the final year.

The mathematical club affords an opportunity for presentation of original papers and discussions of pedagogical and pertinent questions. In the mathematical seminary library are available the standard treatises for study and consultation in connection with the lectures.

The final test of the candidate's power in original investigation is the quality of his thesis. If this is satisfactory, and if he survives the ordeal of a final examination planned to determine the extent of his mathematical attainments, he must, as a final requirement, arrange for the publication of his thesis, in whole or in part, in a manner satisfactory to the department under which he has studied. A small diploma fee is required when the degree is granted.

A summary of the existing conditions at the universities named above follows, the arrangement being topical for the sake of clearness. 


\section{Conditions of Matriculation.}

The bachelor's degree accepted in matriculation is not specifically described at the following institutions, but all such degrees are considered equivalent : Cincinnati, Illinois, Missouri, Stanford, Syracuse, Virginia, Yale.

"Graduates of this or other institutions in which the bachelor's degree is awarded for courses equivalent to those given at this institution " are accepted at Bryn Mawr, Chicago, Cornell, Kansas, Nebraska, Wisconsin.

A bachelor's degree from a college "in good standing" is required by Brown, California, Clark, Columbia, Johns Hopkins, Princeton, Pennsylvania.

Harvard University requires a bachelor's degree of "substantial character."

At Michigan the credentials of the candidates are examined by the Graduate Council.

It appears that, at the majority of the institutions in question (16 out of $2 t$ ), the mere attainment of the first degree is not deemed sufficient, but the value of the degree in educational units is decisive.

\section{Language Requirement.}

All institutions prescribe a "good reading knowledge" of French and German. The practical point is that the candidate may have to consult treatises and memoirs in French, German, or Italian, and his linguistic knowledge must suffice for this purpose. In addition, Bryn Mawr specifies " some knowledge" of Latin as a requirement, and at Brown and Yale a "good knowledge" of Latin is required unless for some excellent reason the candidate is excused by the faculty.

\section{Time Element.}

One year of continuous residence is required in all cases save by Bryn Mawr (2 years), Chicago ( $1 \frac{1}{2}$ years), Columbia ( 2 years).

Work of equal grade in other universities is generally credited for courses in the early graduate years.

It appears, as a rule, that three years of graduate study are necessary for securing the doctorate.

$$
\text { Prescribed Courses - Number of Courses. }
$$

Rigidly prescribed graduate courses in mathematics do not, as a rule, exist. Specific exceptions are the following: 
Courses totalling 20 hours for one year at Clark University. The titles of the courses are analytic geometry of higher plane curves, skew curves and surfaces, differential equations and calculus of variations, real and complex function theory including elliptic functions, theory of numbers, modern synthetic geometry, theory of substitutions, invariants, finite differences.

Undergraduate courses amounting to 8 hours for a year at Yale University. The subjects are projective geometry, advanced calculus, mechanics, function theory.

The courses just mentioned are doubtless required at all institutions in which degrees have been awarded, without specific mention of this fact.

The amount of work required is also not generally defined. There are some exceptions. At Yale, a candidate must have successfully followed graduate courses amounting to 18 hours for a year. At Columbia, a minimum of 15 hours is required; at Virginia, 9 hours of lectures each year; at Pennsylvania, 24 year-hours.

The essential point is, of course, that the candidate must prepare himself for the final examination. To make a comparison of the exacting nature of this work in various institutions is difficult and perhaps impossible. The same course (in name) might well be quite vigorously conducted at one university, and at another partake of an easy character. On the other hand, the breadth of study required can easily be determined by taking into consideration minor subjects (see the next section).

\section{Minors.}

The requirement as to minor subjects at Harvard University is quite definite. From the following four divisions of mathematics: I. Geometry, II. Arithmetic and algebra, III. The differential and integral calculus and the theory of functions, IV. Mechanics and mathematical physics, the candidate must designate one as his chosen field, his major. In each of two of the other three, he must present a thesis on a topic assigned to him. "These minor theses are intended to test the capacity of the candidate to prepare, at short notice, brief expositions of subjects with which he has had previously little or no acquaintance. While no strictly original work is expected on these theses, the form of presentation must be original."

Minor subjects (one or two) are as a rule required, but not specified. Princeton offers an exception in specifying philosophy 
and a cognate subject. At Wisconsin, one minor must be studied for two years, a second minor for one year.

At Yale, the requirement of 18 year-hours of graduate courses results in general in the pursuance of courses distributed among three of the main divisions in the Harvard scheme.

Mathematical physics is very generally recommended as a minor.

\section{Final Examination.}

Examinations in course are held by Columbia, Harvard, Illinois, Kansas, Missouri, Northwestern, Pennsylvania, Syracuse, Virginia, Wisconsin, Yale.

A formal, final oral examination is required after acceptance of the thesis at the following universities: Chicago, Clark, Columbia, Harvard, Minnesota, Nebraska, Northwestern, Princeton, Wisconsin.

The final examination may be both oral and written at these institutions : Bryn Mawr, California, Cincinnati, Cornell, Illinois, Johns Hopkins, Kansas, Michigan, Missouri, Stanford, Syracuse, Yale.

Yale offers an exception to the general rule of holding a final examination at the end of the candidate's course. At Yale, the examination takes place at the end of the last year but one, or at the beginning of the last year. This determination of the candidate's attainments before work on the thesis is begun is intended as a check.

The final examination is public except at Clark, Cornell, Minnesota, Pennsylvania, and Yale.

Virginia requires no final examination; Pennsylvania, a written examination.

\section{Publication of Thesis.}

Publication of the thesis, in whole or in part, is a requirement at all institutions (page 1) except Brown, Harvard, Michigan, Minnesota.

Special conditions imposed are :

There must be deposited in the university library : 150 copies (Bryn Mawr), 25 copies (Northwestern), 100 copies (Clark), 100 copies (Chicago, Cincinnati, Illinois, Nebraska, Virginia, Wisconsin), 50 copies (Cornell), 30 copies (Columbia).

Printing of the entire thesis is required by Bryn Mawr, Chicago, Cincinnati, Columbia, Indiana, Northwestern, Pennsylvania, Princeton, Syracuse, Virginia.

Acceptance by a reputable journal of the whole or part suf- 
fices at Clark, Cornell, Johns Hopkins, Indiana, Illinois, Michigan, Missouri, Nebraska, Pennsylvania, Yale.

At Harvard, doctors' dissertations have "almost invariably been published."

\section{Various.}

A small diploma fee is usually required. This varies from five dollars to sixty dollars (Princeton).

The master's degree is in no case a prerequisite for the doctorate, but is recommended at Chicago, Cincinnati, Columbia, Illinois, Kansas, Minnesota, Missouri.

\section{Research and Special Courses.}

The candidate's ability for original investigation is, in general, stimulated through work in seminaries. Topics assigned to him for private research develop this faculty, and criticism and personal conference with his instructors further the same end. Seminary work consists in discussion and criticism of original papers presented by candidates. Reports on current literature are also called for, in particular on contributions to those special lines in which students and instructors are peculiarly interested.

\section{Equipment-Special Features.}

Collections of mathematical models are available, in all institutions, for study by the candidate. At Yale, a special room is equipped with all necessary tools for the making, by the student, of simple models. With the development of graduate clubs at universities throughout the United States has come the establishment in each institution of a mathematical club. At Harvard the club is conducted entirely by the students, members of the faculty attending as guests. The organization at Yale differs from this only in the existence of faculty supervision through the secretary of the club, who is a full professor. This supervision is nominal. In general it may be said that the mathematical club is an informal affair, professors and students meeting for extra-curriculum intercourse and for discussion of such papers and reports as may be presented by faculty and students without obligation so to do.

The library facilities are reported as adequate for all lines of mathematical research, save at Indiana, Kansas, Michigan, Minnesota, Syracuse, and Wisconsin. In addition to the resources of the university library there exists at many institutions a seminary library in which are available current mathematical treatises and periodicals-duplicates of those stored in the main library. 
The library of the American Mathematical Society is rapidly becoming for its members a most valuable possession. By exchange, files of all periodicals and proceedings are being completed and these are made available to members wherever located through the regular means of transportation.

\section{Degrees Granted.}

Within the years $1900-09$, the doctorate in mathematics has been conferred upon approximately 135 candidates, the number at the various institutions being as indicated (in a few cases round numbers are given):

Bryn Mawr 1, California 1, Chicago 30, Clark 9, Columbia 10, Cornell 14, Harvard 12, Illinois 1, Johns Hopkins 20, Kansas 1, Pennsylvania 8, Princeton 3, Stanford 1, Syracuse 1, Virginia 4, Wisconsin 4, Yale 21.

\section{Conditions in the Faculties.}

At Clark, Chicago, and Johns Hopkins certain members of the mathematical faculties give graduate instruction only. The number of hours per week of such instruction is respectively : Clark 7, Chicago 6-8, Johns Hopkins 4-7.

In general, graduate instruction is compensated for by a reduction in undergraduate hours. The following table makes clear the policy followed in the various institutions, the first number indicating the hours per week of undergraduate, the second of graduate instruction :

\begin{tabular}{|c|c|c|c|}
\hline Bryn Mawr & 9 & and & 3 \\
\hline Chicago & 6 & 66 & 4 \\
\hline Columbia & 6 & 66 & 6 or 9 and 3 \\
\hline Cornell & 11 & 6، & 4 \\
\hline Harvard & $4 \frac{1}{2}$ & 6 & $4 \frac{1}{2}$ and a reading course \\
\hline Illinois & 10 & 66 & 3 \\
\hline Indiana & 5 & 66 & 4 or 5 and 6 \\
\hline Kansas & 7 & “6 & 5 or 10 and 3 , or 15 and 0 \\
\hline Michigan & 12 & 66 & 3 \\
\hline Minnesota & 11 & 66 & 3 \\
\hline Missouri & 10 & 6 & 2 or 10 and 3 \\
\hline Nebraska & 10 & 66 & 3 or 15 ، 0 \\
\hline Northwestern & 6 & 66 & 6 or 10 " 3 \\
\hline Penusylvania & 10 & 6 & 3 \\
\hline Princeton & 6 & “6 & 3 or 9 and 3 \\
\hline Stanford & 10 & "6 & 0 \\
\hline Syracuse & 6 & 66 & 6 \\
\hline Virginia & 12 & 66 & 2 \\
\hline Yale & 10 & 66 & 3 \\
\hline
\end{tabular}

